\title{
Composição e abundância relativa dos mamíferos de médio e grande porte no Parque Estadual do Turvo, Rio Grande do Sul, Brasil
}

\author{
Carlos B. Kasper ${ }^{1}$; Fábio D. Mazim ${ }^{2}$; José B. G. Soares ${ }^{3}$; Tadeu G. de Oliveira ${ }^{4}$ \& Marta E. Fabián ${ }^{5}$ \\ ${ }^{1}$ Rui Barbosa, Caixa Postal 121, 95940-000 Arroio do Meio, Rio Grande do Sul, Brasil. \\ 2 Rua Padre Anchieta 1277, ap. 201, Centro, 96015-420 Pelotas, Rio Grande do Sul, Brasil. \\ ${ }^{3}$ Rua Coronel Mario Maciel Costa 344, 96330-000 Arroio Grande, Rio Grande do Sul, Brasil. \\ ${ }^{4}$ Rua das Quaresmeiras, Quadra 8, 14, 65076-270 São Luiz, Maranhão, Brasil. \\ 5 Departamento de Zoologia, Instituto de Biociências, Universidade Federal do Rio Grande do Sul. \\ Avenida Bento Gonçalves 9500, Prédio 43435, 91540-000 Porto Alegre, Rio Grande do Sul, Brasil.
}

\begin{abstract}
Composition and relative abundance of the medium-large sized mammals of Turvo State Park, Rio Grande do Sul, Brazil. Between January of 2005 and December of 2006, studies on the composition and relative abundance of medium and large sized mammals were carried out in Turvo State Park. Records came from camera-trapping, in addition to visualization and presence and absence data from track surveys along pre determined transects. At total, 29 species of medium-large sized mammals were listed. Of these, Dasyprocta azarae Lichtenstein, 1823 and Sylvilagus brasiliensis (Linnaeus, 1758) were the most frequently found. For carnivores, the majority of records were for Nasua nasua (Linnaeus, 1766) and Leopardus pardalis (Linnaeus, 1758), whereas Leopardus tigrinus (Schreber, 1775), Leopardus wiedii (Schinz, 1782) and Galictis cuja (Molina 1782), had the least. Among the ungulates, only Pecari tajacu (Linnaeus, 1758) showed frequent records, ranking fourth overall. Some species, common to other environments, showed few records at Turvo State Park, such as Dasypus novemcinctus Linnaeus, 1758 and Didelphis albiventris Lund, 1840. Data was suggestive of the probable local extinction of Tayassu pecari(Link, 1795) in the Park. The conservation of the medium and large sized mammals of this conservation area is strongly associated with the conservation of the "Misiones Green Corridor", which probably represents a source area for many species. KEY WORDS. Camera-trap; mammalian fauna; Misiones; tracks.
\end{abstract}

RESUMO. Entre janeiro de 2005 e dezembro de 2006 foram realizados estudos sobre a composição e abundância relativa dos mamíferos de médio e grande porte do Parque Estadual do Turvo. Para tanto, foram utilizados registros de armadilhas fotográficas além de visualizações e dados sobre presença e ausência de pegadas ao longo de transectos pré-determinados. No total foram registradas 29 espécies de mamíferos de médio e grande porte, das quais Dasyprocta azarae Lichtenstein, 1823 e Sylvilagus brasiliensis (Linnaeus, 1758) foram as espécies com maior número de registros. No que se refere a Carnivora, Nasua nasua (Linnaeus, 1766) e Leopardus pardalis (Linnaeus, 1758) tiveram os maiores índices de registro, enquanto Leopardus tigrinus (Schreber, 1775), Leopardus wiedii (Schinz, 1782) e Galictis cuja (Molina 1782) os menores. Entre os ungulados apenas Pecari tajacu (Linnaeus, 1758) mostrou-se freqüente, sendo a quarta espécie em número de registros. Algumas espécies comuns em outros ambientes apresentaram baixos índices de registro no Parque Estadual do Turvo, tais como Dasypus novemcinctus Linnaeus, 1758 e Didelphis albiventris Lund, 1840. Finalmente, constata-se a provável extinção local de Tayassu pecari (Link, 1795), uma vez que não foram obtidos registros de sua presença ao longo do estudo. A conservação dos mamíferos de médio e grande porte do Parque está fortemente associada à preservação do “Corredor Verde de Misiones", que provavelmente representa uma área fonte para diversas espécies.

PALAVRAS-CHAVE. Armadilhas fotográficas; mastofauna; Misiones; pegadas.

O Rio Grande do Sul possui 25 unidades de conservação em nível estadual e federal, das quais o Parque Estadual do Turvo (PET) figura como o mais bem preservado e importante (LEMA 1980). O Parque é o único local do Estado a apresentar registros recentes de espécies como Panthera onca (Linnaeus, 1758), Tapirus terrestris (Linnaeus, 1758) e Tayassu pecari (Link, 1795)
(Lema 1980, Albuquerque 1985) consideradas como Criticamente em Perigo conforme Livro Vermelho das Espécies da Fauna Ameaçada no Rio Grande do Sul (Fontana et al. 2003). Além disso, as populações de $P$. onca, $T$. pecari e da T. terrestris da região de Misiones, são as mais austrais destas espécies (OliveIRA 1994, EIsemberg \& RedFord 1999). 
Para o PET são citadas 30 espécies de mamíferos de médio porte (Wallauer \& Albuquerque 1986), muitas das quais ameaçadas de extinção como Puma concolor (Linnaeus, 1771), Leopardus pardalis (Linnaeus, 1758), Eira barbara (Linnaeus, 1758), Pecari tajacu (Linnaeus, 1758), Cuniculus paca (Linnaeus 1766), entre outros (FonTANA et al. 2003). Embora de grande relevância, o PET carece de estudos sobre a ecologia das comunidades animais que nele residem (Albuquerque 1985). A carência de dados sobre os mamíferos do Parque Estadual do Turvo reflete-se na ausência de referências recentes, uma vez que a maioria dos dados sobre a região remonta à década de 1980 ou anterior (AlbUQUerQue 1977, 1985, Lema 1980, Wallauer \& Albuquerque 1986). Após este período, poucos trabalhos acrescentaram dados sobre a mastofauna do Parque, como RuI \& Fabián (1997) sobre espécies de quirópteros da família Phyllostomidae.

Embora o monitoramento de espécies dependa de estimativas populacionais (CARBONE et. al. 2001), a grande maioria das áreas de preservação não conta sequer com inventários que determinem parâmetros de biodiversidade (CERQueIra 2001).

Entre os mamíferos há grande diversidade de hábitos e, por conseguinte, de padrões corporais que exigem a aplicação de métodos variados para a determinação de parâmetros ecológicos (Voss \& Emmons 1996). Métodos baseados na identificação de pegadas, visualizações ao longo de transectos lineares e o uso de armadilhas fotográficas têm sido tradicionalmente utilizados no estudo dos mamíferos de médio e grande porte (PARDINI et al. 2003, Cullen Jr \& Rudran 2003, Tomas \& Miranda 2003).

As armadilhas fotográficas vêm sendo utilizadas desde o início do século XX e podem ser consideradas ideais para o monitoramento da abundância relativa de mamíferos de médio e grande porte (Wemmer et al. 1996). O uso de armadilhas fotográficas mostra-se particularmente útil no estudo de espécies com hábitos noturnos, furtivos ou que ocorram em baixas densidades (Tomas \& Miranda 2003), pois permite o monitoramento de diversos pontos, por longos períodos. Estes equipamentos vêm sendo utilizados na determinação de parâmetros populacionais de espécies crípticas e aquelas cujo padrão de coloração é distintivo como Panthera tigris (Linnaeus, 1758) (Karanth 1995, Karanth \& Nichols 1998, Carbone et al. 2001), Panthera onca (Wallace et al. 2003, Mafei et al. 2004) e L. pardalis (Trolle \& Kéry 2003, Di BitetTi et al. 2006).

Assim, este estudo tem por objetivo analisar a composição da comunidade de mamíferos de médio e grande porte do Parque Estadual do Turvo e obter dados sobre a abundância relativa destas espécies através da aplicação de diferentes métodos. Finalmente, com base nos estudos populacionais realizados, pretende-se discutir as implicações destas informações para conservação da mastofauna na área.

\section{MATERIAL E MÉTODOS}

O Parque Estadual do Turvo é uma das maiores unidades de conservação do Rio Grande do Sul, com 17491 ha. Localizase no município de Derrubadas, extremo noroeste do Estado, divisa com a Argentina e com o Estado de Santa Catarina, entre as coordenadas $27^{\circ} 00^{\prime} \mathrm{S}, 53^{\circ} 40^{\prime} \mathrm{W}$ a $27^{\circ} 20^{\prime} \mathrm{S}, 54^{\circ} 10^{\prime} \mathrm{W}$ (Fig. 1).
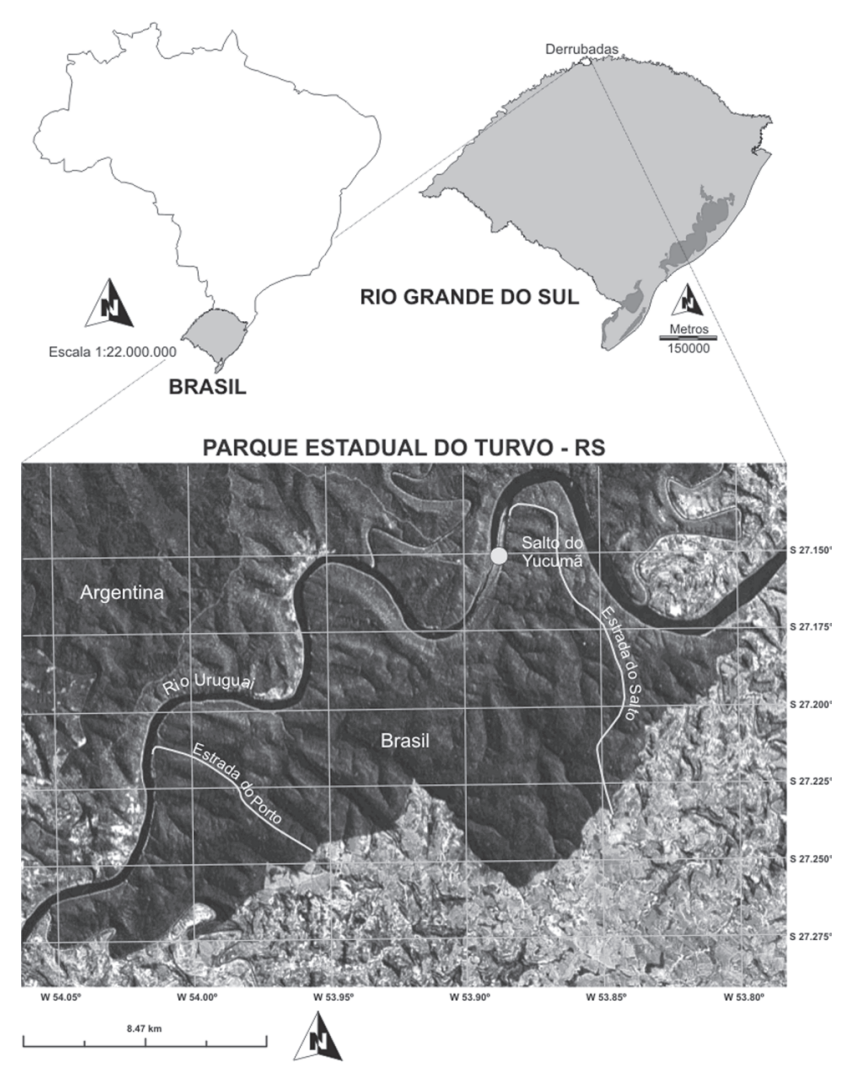

Figura 1. Mapa de localização do Parque Estadual do Turvo.

A vegetação é um dos últimos redutos representativos da Mata Pluvial do Alto Uruguai, que ocupava uma grande área das bacias hidrográficas dos rios Paraná e Uruguai (Brack et al. 1985). Segundo estes autores, foram identificadas 727 espécies vegetais na área do Parque, onde podem ser distinguidas cinco formações que incluem as matas propriamente ditas, vegetação associada a banhados, áreas campestres (afloramentos do embasamento basáltico), vegetação secundária e dos lajedos.

A área de estudo compreende duas porções desta unidade, localizadas ao longo das duas estradas principais do Parque. Uma das áreas corresponde à estrada que leva ao Salto do Yucumã (Estrada do Salto) que possui $15 \mathrm{~km}$ de extensão e é aberta ao público durante cinco dias por semana, das 8:00 às 17:00 h. Junto à sede da Unidade, distante aproximadamente $15 \mathrm{~km}$ da estrada do Salto, há outra estrada que estende-se do alojamento do Parque ao Porto Garcia no Rio Uruguai. Esta estrada, denominada Estrada do Porto, que possui $8 \mathrm{~km}$ de extensão e é restrita a pesquisadores e funcionários do Parque, constitui a segunda área do estudo.

Os métodos empregados no inventário da fauna de mamíferos e na obtenção de dados sobre a abundância relativa

Revista Brasileira de Zoologia 24 (4): 1087-1100, dezembro 2007 
basearam-se no uso de armadilhas fotográficas, identificação de rastros e em visualizações. Além das estradas mencionadas, foram utilizadas trilhas que não se distanciaram mais do que $500 \mathrm{~m}$ destes percursos.

\section{Armadilhas fotográficas}

Ao longo do ano de 2005, utilizaram-se armadilhas fotográficas com um distanciamento médio de $2 \mathrm{~km}$ entre cada estação. As estações foram, sempre que possível, compostas por duas câmeras dispostas frente a frente, uma em cada lado da estrada, de forma a registrar ambos os flancos do animal. Embora o distanciamento de $2 \mathrm{~km}$ tenha sido mantido durante todo o trabalho, na sétima campanha de campo, correspondente ao mês de julho, a maioria das estações foi relocada, fazendo com que a estrada fosse mais uniformemente amostrada. Assim, ao longo do estudo amostrou-se cada trecho de $1 \mathrm{~km}$ de ambas as estradas.

$\mathrm{Na}$ estrada do Salto foram dispostas oito estações mantidas por períodos mensais de quatro noites entre janeiro e dezembro, à exceção de outubro quando não foi possível a realização da atividade de campo. Esta disposição resultou num esforço amostral de 312 armadilhas noite. Na estrada do Porto foram dispostas quatro estações, mantidas por períodos de quatro a 14 noites, tempo necessário para o preenchimento do filme fotográfico, término das baterias ou ocorrência de problemas técnicos. Tal disposição resultou num esforço amostral de 402 armadilhas noite.

Durante o ano de 2006 uma nova disposição de câmeras foi utilizada, abrangendo de forma intensiva uma porção de aproximadamente $1 \mathrm{~km}^{2}$. As áreas escolhidas para a amostragem intensiva correspondem às porções finais da estrada do Salto e estrada do Porto, com uma distância de aproximadamente 12 $\mathrm{km}$ uma da outra. Ambas as áreas localizam-se próximas ao Rio Uruguai, possuindo características ambientais semelhantes.

Neste caso, foram dispostas oito estações, sendo quatro junto à estrada e quatro em trilhas abertas perpendicularmente à estrada com um espaçamento médio de 300 m entre estações. As armadilhas permaneceram em campo por 60 dias, totalizando um esforço amostral de 480 armadilhas noite. Na estrada do Porto o levantamento intensivo ocorreu entre os meses de março e maio de 2006 e na área do Salto entre maio e agosto do mesmo ano.

Não obstante, os estudos sobre a comunidade de mamíferos, voltados à determinação da densidade de Panthera onca, prosseguiram no período de agosto a dezembro de 2006. Neste estudo foram dispostas câmeras nas estradas, com distanciamento médio de $3 \mathrm{~km}$, além de câmeras junto aos principais córregos do PET com distanciamento de 4-6 km. Os registros obtidos por este método não foram trabalhados estatisticamente e serviram apenas para o inventário final. Tal método totalizou um esforço amostral adicional de 960 armadilhas noite.

Na utilização de registros fotográficos, cada foto obtida por espécie em cada estação foi considerada como um registro independente, à exceção das fotos com o mesmo horário e/ou fotos duplas obtidas por armadilhas fotográficas dispostas frente a frente. A partir dos registros fotográficos, foram calculados índices de registro, que representam o número de registros fotográficos obtidos a cada 100 armadilhas noite (CPUE).

As armadilhas fotográficas permitiram ainda a análise do período de atividade de diversas espécies. Assim, para as espécies que apresentaram um número razoável de registros ( $>10$ registros) foram determinados os períodos de atividade. Nestas análises foram desconsiderados todos os registros seqüenciais de uma mesma espécie que tenham apresentado diferença menor do que uma hora entre fotos.

\section{Transectos de pegadas}

Para a avaliação da freqüência de pegadas, percorreu-se transectos de $1 \mathrm{~km}$ onde foi verificada a ocorrência das espécies que eram registradas apenas quanto à presença/ausência. Em cada uma das estradas, foram percorridos $8 \mathrm{~km}$ seqüenciais, mensalmente no período de abril a dezembro de 2005. Desta forma foi totalizado um esforço amostral de $128 \mathrm{~km}$ de transectos, sendo $64 \mathrm{~km}$ em cada uma das estradas.

Os dados referentes aos transectos foram analisados apenas quanto à proporção de transectos com, ou sem, o registro da espécie. Assim, embora a utilização de transectos contíguos prejudique a independência dos dados, uma vez que determinados indivíduos podem ter suas pegadas em mais de um transecto, os dados são apresentados apenas de forma a enriquecer a discussão e o inventário de espécies.

Os rastros foram identificados com base em guias de identificação pegadas como Travi \& Gaetani (1985) e Becker \& Dalponte (1991), Oliveira \& Cassaro (2005) além da experiência de campo dos autores.

\section{Visualizações}

Realizaram-se censos visuais durante os transectos de pegadas onde registrou-se a presença de todas as espécies visualizadas. Além disso, registraram-se todas as visualizações ocasionais obtidas durante os deslocamentos no interior do Parque Estadual do Turvo. Registros visuais também foram obtidos a partir de focagens noturnas, nas estradas do Porto e do Salto, percorridas com a utilização de veículo motorizado a aproximadamente $30 \mathrm{~km} / \mathrm{h}$, com o auxílio de holofote de longo alcance.

Tais registros ocorreram de forma aleatória não havendo estimativas do esforço amostral empregado, seja em horas de atividade em campo ou em distância percorrida durante os deslocamentos no interior do Parque. Desta forma os registros obtidos por estes métodos não foram utilizados para análises estatísticas, mas sim para enriquecer a discussão dos dados e ampliar o inventário de espécies, fornecendo uma idéia mais aproximada da composição da comunidade de mamíferos da área de estudo.

\section{Avaliação do status}

Tomando por base os diversos estimadores de abundância relativa supracitados, classificou-se o status das espécies em comum, freqüente, pouco freqüente e rara. Considerou-se como comuns aquelas espécies com elevada presença de registros em qualquer dos estimadores. Freqüentes foram aquelas com ocor- 
rência mediana, pouco freqüentes as de baixa quantidade de registros, enquanto as raras foram aquelas com registros muito baixos. Esta classificação objetivou apenas sintetizar as diversas formas de registro dando uma idéia do status das mesmas. A classificação reflete a proporção de registros obtidos pelos métodos aplicados, que sem dúvida apresentam diversos vieses em função da biologia das diferentes espécies.

\section{Comparação entre áreas e períodos de amostragem}

De forma a avaliar possíveis diferenças quantitativas da comunidade de mamíferos ocorrentes junto às duas estradas e entre as estações do ano, foram comparadas a abundância, riqueza de espécies e equitabilidade através da análise de variância (ANOVA) (SOKAL \& RoHLF 1995) de fator duplo (comparando os registros obtidos na estrada do Porto com os registros obtidos na estrada do Salto, a cada período estacional). Para as comparações da composição de espécies foi utilizado Análise de Similaridade (ANOSIM) (CLARKe \& GREEN 1998) a partir dos índices de Morisita e Jaccard (também comparando estrada do Porto "versus" estrada do Salto, sazonalmente). Todas os cálculos foram realizados com a utilização do software PASt (HAMMER et al. 2001) Estas análises foram realizadas apenas com os dados obtidos no ano de 2005. Para tanto, todos os dados foram transformados de forma a obter um índice de captura por unidade de esforço, equivalente a 100 armadilhas noite. Tal padronização objetivou equivaler todos os dados a um período de 24 horas, uma vez que em alguns casos, algumas câmeras permaneceram desligadas no período diurno, havendo portanto, um esforço de campo desigual entre dia e noite.

\section{RESULTADOS}

Obteve-se o registro de 29 espécies, distribuídas nas seguintes ordens: três Didelphimorphia, três Xenarthra, dois Primates, 12 Carnivora, três Artiodactyla, um Perissodactyla, três Rodentia e dois Lagomorpha. Destas, quatro espécies constituem novos registros para área (Tab. I). A nomeclatura segue à adotada por Reis et al. (2006).

\section{Armadilhas fotográficas}

A partir do uso de armadilhas fotográficas obteve-se o registro de 25 espécies, das quais 20 ocorreram durante a primeira fase do projeto, três novas espécies nos estudos intensivos de 2006 e duas com o esforço adicional empregado em 2006. Para três espécies, Tamandua tetradactyla (Linnaeus, 1758), Euphractus sexcintus (Linnaeus, 1758) e Lepus capensis (Linnaeus, 1758), este método constituiu a única forma de registro.

Durante as duas primeiras fases do projeto obteve-se 1605 registros fotográficos de 23 espécies. As espécies que apresentaram maior número de registros foram Dasyprocta azarae Lichtenstein, 1823 (432 fotos), Sylvilagus brasiliensis (Linnaeus, 1758) (334 fotos), Leopardus pardalis (211 fotos) e Pecari tajacu (196 fotos), que juntas representaram mais de 70\% dos registros fotográficos (Tab. II). As espécies com menor número de registros foram Leopardus tigrinus (Schreber, 1775) e Leopardus wiedii (Schinz, 1782) (uma foto cada), Lepus capensis (duas fotos), Cebus nigritus (Goldfuss, 1809) e Tamandua tetradactyla (ambas com três fotos), Panthera onca e Hydrochoerus hydrochaeris (Linnaeus, 1766) (ambas com quatro fotos cada), Puma concolor (cinco fotos) Didelphis albiventris Lund, 1840 (seis fotos) e Dasypus novemcinctus Linnaeus, 1758 (oito fotos) que juntas representam pouco mais de $2 \%$ dos registros fotográficos (Tab. II). Além destas, duas espécies foram fotografadas apenas com a aplicação de um esforço amostral adicional de 960 armadilhas noite: Cuniculus paca e Euphractus sexcintus.

\section{Períodos de atividade}

O período de atividade de diversas espécies denota diferenças temporais na utilização de nichos semelhantes. Entre as duas espécies com maior número de registros Dasyprocta azarae e Sylvilagus brasiliensis verifica-se uma notável diferença nos períodos de atividade, com a primeira sendo exclusivamente diurna e a segunda exclusivamente noturna (Fig. 2). Entre os felinos, fica clara a utilização preferencial do período noturno por Leopardus pardalis e do período diurno por Puma yagouaroundi (Lacépède, 1809) (Fig. 3), que foi a segunda espécie de felino em número de registros. Com os demais carnívoros, duas espécies apresentam-se predominantemente noturnas, Procyon cancrivorus (Cuvier, 1798) e Cerdocyon thous (Linnaeus, 1766), e duas preferencialmente diurnas, Nasua nasua (Linnaeus, 1766) e Eira barbara (Fig. 4). Entre os ungulados, percebe-se a utilização preferencial do período diurno por Pecari tajacu e do período noturno por Mazama sp. e Tapirus terrestris (Fig. 5).

\section{Transectos de pegadas}

Os transectos de pegadas permitiram a identificação de 20 espécies, sendo este o único método de registro para duas delas: Chironectes minimus (Zimmermann, 1780) e Lontra longicaudis (Olfers, 1818). Na estrada do Porto foram identificadas 19 espécies enquanto na estrada do Salto foram identificadas 16 espécies.

A espécie mais constante nos transectos de pegadas foi Dasyprocta azarae, cujas pegadas foram encontradas em $94 \%$ dos trechos de um quilômetro percorridos. Com ocorrência marcante destacam-se também Pecari tajacu, presente em 55\% dos transectos, Tapirus terrestris presente em 53\% dos trechos percorridos, Sylvilagus brasiliensis com pegadas em 49\% dos trechos de $1 \mathrm{~km}$, Leopardus pardalis, cujas pegadas foram observadas em $46 \%$ dos transectos, e Mazama sp. presente em 39\% dos transectos. As espécies com menor número de registros foram Chironectes minimus e Cuniculus paca, ocorrentes em 1\% dos transectos, Didelphis sp., presente em $3 \%$, Hydrochoerus hydrochaeris, presente em 4\%, e Leopardus tigrinus em $8 \%$ dos trechos percorridos. Duas espécies tiveram suas pegadas encontradas apenas fora dos transectos de pegadas: Lontra longicaudis e Puma concolor (Tab. II).

\section{Visualizações}

Obteve-se 327 registros visuais, num total de 580 indivíduos, de 16 espécies. Destas, Galictis cuja (Molina 1782), teve nos registros visuais a única forma de registro.

As espécies com maior número de registros foram Sylvilagus 
Tabela I. Lista de mamíferos registrados no Parque Estadual do Turvo, método de registro da espécie neste estudo e referências anteriores. (Rf) Registro fotográfico, (Pg) pegadas, (Vi) visualização e/ou vocalização, (1) Wallauer \& AlbuQUerque (1986), (2) RUI \& FABián (1997), (3) SILva et al. (2005).

Táxon Nome popular

Forma de Registro

Referências anteriores

Didelphimorphia

Chironectes minimus (Zimmermann, 1780)

Cuíca d'água

$\mathrm{Pg}$

Gracilinanus agilis (Burmeister, 1854)

Didelphis albiventris Lund, 1840

Didelphis aurita (Wied, 1826)

Monodelphis henseli (Thomas, 1888)

Xenarthra

Tamandua tetradactyla (Linnaeus, 1758)

Dasypus novemcinctus Linnaeus, 1758

Cuica

$-$

Gambá de orelha branca

Rf, Pg

3

Gambá de orelha preta

Rf, Pg, Vi

Guiquica

- 1

Tamanduá mirim

Tatu galinha

Rf

Tatu mulita

$\mathrm{Rf}, \mathrm{Pg}$

Dasypus septecinctus Linnaeus, 1758

Euphractus sexcintus (Linnaeus, 1758)

Chiroptera

Artibeus fimbriatus Gray, 1838

Artibeus Ituratus (Olfers, 1818)

Chrotopterus auritus (Peters, 1856)

Desmodus rotundus (Geoffroy, 1810)

Pygoderma bilabiatun (Wagner, 1843)

Sturnira lilium (Geoffroy, 1810)

Myotis ruber (Geoffroy, 1806)

Tadarida brasiliensis (Geoffroy, 1824)

Noctilio leporinus (Linnaeus, 1758)

Primates

Alouatta guariba Cabrera, 1940

Cebus nigritus (Goldfuss, 1809)

Carnivora

Cerdocyon thous (Linnaeus, 1766)

Nasua nasua (Linnaeus, 1766)

Procyon cancrivorus (Cuvier, 1798)

Eira barbara (Linnaeus, 1758)

Tatu peludo

$-$

Rf

Morcego fruteiro

Morcego fruteiro

Morcego bombachudo

Morcego vampiro

Morcego

Morcego beija flor

Morcego borboleta vermelho

Morcego das casas

Morcego pescador

Bugiu ruivo

Macaco prego

Rf, Vi

1,3

Graxaim do mato

Rf, Pg, Vi

Rf, Pg, Vi

Rf, Pg, Vi

Rf, Pg, Vi

1,3

Galictis cuja (Molina 1782)

Galictis vittata (Schreber, 1776)

Lontra longicaudis (Olfers, 1818)

Leopardus pardalis (Linnaeus, 1758)

Leopardus tigrinus (Schreber, 1775)

Leopardus wiedii (Schinz, 1782)

Panthera onca (Linnaeus, 1758)

Coati

Mão pelada

Irara

Furão

Furão grande

Lontra

Jaguatirica

Gato do mato pequeno

Gato maracajá

Onça pintada

Puma

Puma yagouaroundi (Lacépède, 1809)

Gato mourisco

$\mathrm{Vi}$

$-$

$\mathrm{Pg}$

Rf, Pg, Vi 1, 3

$\mathrm{Rf}, \mathrm{Pg}$

3

Rf, Pg

$\mathrm{Rf}, \mathrm{Pg}$

Rf, Pg, Vi

1

Artiodactyla

Mazama americana (Erxleben, 1777)

Mazama gouazoupira (Fischer, 1814)

Veado mateiro

Rf, Pg, Vi

1,3

1

1,3

Veado catingueiro

Rf, Pg, Vi

1,3

Veado bororó

$-$

Rf, Pg, Vi

Rf, Pg, Vi

Cateto

Pecari tajacu (Linnaeus, 1758)

(

1,3

1,3

1,3

1,3

1,3

3

1,3

Continua

Revista Brasileira de Zoologia 24 (4): 1087-1100, dezembro 2007 
Tabela I. Continuação.

\begin{tabular}{|c|c|c|c|}
\hline Táxon & Nome popular & Forma de Registro & Referências anteriores \\
\hline \multicolumn{4}{|l|}{ Perissodactyla } \\
\hline Tapirus terrestris (Linnaeus, 1758) & Anta & $\mathrm{Rf}, \mathrm{Pg}, \mathrm{Vi}$ & 1,3 \\
\hline \multicolumn{4}{|l|}{ Rodentia } \\
\hline Coendou spinosus (Cuvier, 1822) & Ouriço cacheiro & - & 1 \\
\hline Cuniculus paca (Linnaeus 1766) & Paca & $\mathrm{Rf}, \mathrm{Pg}$ & 1,3 \\
\hline Dasyprocta azarae Lichtenstein 1823 & Cutia & Rf, Pg, Vi & 1,3 \\
\hline Hydrochoerus hydrochaeris (Linnaeus, 1766) & Capivara & $\mathrm{Rf}, \mathrm{Pg}$ & 1 \\
\hline Sciurus aestuans Linnaeus 1776 & Serelepe & - & 1 \\
\hline \multicolumn{4}{|l|}{ Lagomorpha } \\
\hline Lepus capensis (Linnaeus, 1758) & Lebre & $\mathrm{Rf}$ & \\
\hline Sylvilagus brasiliensis (Linnaeus, 1758) & Tapiti & $\mathrm{Rf}, \mathrm{Pg}, \mathrm{Vi}$ & 1,3 \\
\hline
\end{tabular}
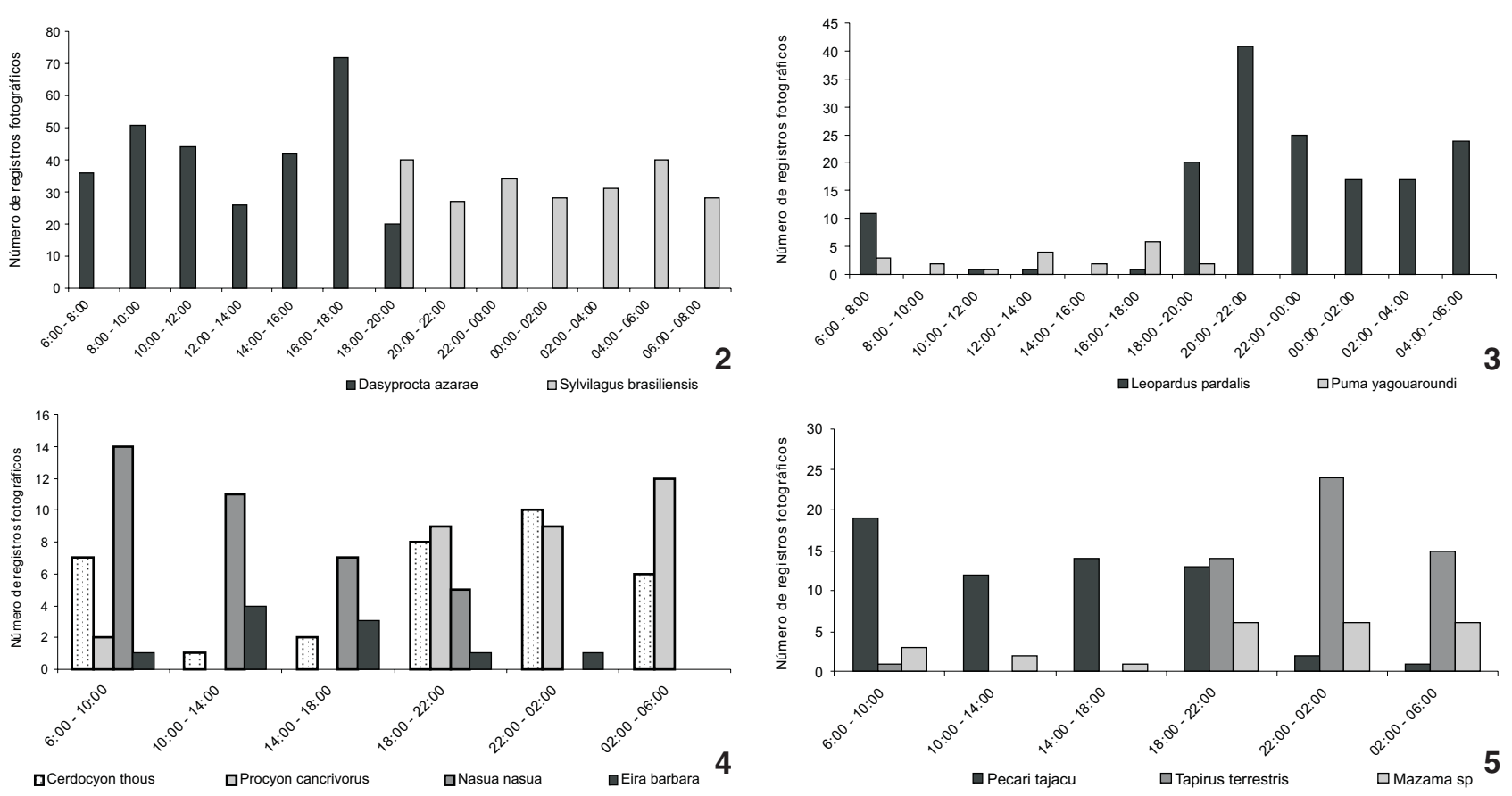

Figuras 2-5. Período de atividade de: (2) Dasyprocta azarae e Sylvilagus brasiliensis; (3) Leopardus pardalis e Puma yagouaroundi ; (4) Cerdocyon thous, Procyon cancrivorus, Nasua nasua e Eira barbara; (5)Pecari tajacu, Tapirus terrestris e Mazama sp., observados no Parque Estadual do Turvo a partir do uso de armadilhas fotográficas.

brasiliensis e Dasyprocta azarae com 139 e 105 visualizações, respectivamente. Além destas, três espécies de hábitos gregários foram visualizadas com freqüência: Nasua nasua, com 23 visualizações e um total de 165 animais, Pecari tajacu, com 18 visualizações e um total de 82 indivíduos, e Cebus nigritus, que foram visualizados em nove ocasiões totalizando 42 animais (Tab. II). Comparação entre áreas e períodos de amostragem

As análises indicam existir variação na abundância dos indivíduos tanto entre as estradas $(F=34,96 ; p=0,0078)$ quan- to entre as estações do ano ( $F=12,45 ; \mathrm{p}=0,0387)$. A abundância média observada foi de $132,13( \pm 26,78)$ registros a cada 100 armadilhas noite na estrada do Salto ante 103,56 $( \pm=21,47)$ registros a cada 100 armadilhas noite na estrada do Porto.

No que se refere à riqueza não houve diferença significativa entre estações do ano $(\mathrm{F}=5,66 ; \mathrm{p}=0,0942)$ nem entre estradas $(F=0,82 ; p=0,4309)$. A riqueza média de espécies foi de $11,5( \pm 1,04)$ e $10,25( \pm 2,29)$ a cada estação climática, nas estradas do Porto e Salto, respectivamente. 
Tabela II. Lista de mamíferos de médio e grande porte registradas no Parque Estadual do Turvo, número e porcentagem dos registros fotográficos obtidos, freqüência de transectos com pegadas ao longo de $128 \mathrm{~km}$, número de visualizações e número de animais visualizados em 2005, e status de ocorrência baseado nas freqüências de registro. (C) Comum, (F) freqüente, (PF) pouco freqüente, (R) raro, (EX) estinto, (NR) espécie não registrada neste estudo, (?) poucos dados, $\left({ }^{*}\right)$ registro com o esforço adicional, $\left({ }^{* *}\right)$ registros por vocalização, $\left({ }^{* * *}\right)$ valor referente à proporção de pegadas de Didelphis spp.

\begin{tabular}{|c|c|c|c|c|c|}
\hline \multirow{2}{*}{ Espécies } & \multicolumn{2}{|c|}{ Registros fotográficos } & \multirow{2}{*}{ Pegadas } & \multirow{2}{*}{$\frac{\text { Visualizações }}{\text { n (ocasiões) }}$} & \multirow{2}{*}{ Status de ocorrência } \\
\hline & $\mathrm{N}$ & $\%$ & & & \\
\hline Chironectes minimus & - & - & 0,010 & - & $\mathrm{R}$ \\
\hline Didelphis albiventris & 6 & 0,37 & \multirow{2}{*}{$0,030 * * *$} & - & $\mathrm{R}$ \\
\hline Didelphis aurita & 11 & 0,69 & & 3 & PF \\
\hline Dasypus novemcinctus & 8 & 0,50 & 0,050 & - & $\mathrm{PF}$ \\
\hline Dasypus sepetecinctus & - & - & - & - & NR \\
\hline Euphractus sexcinctus & $1 *$ & - & - & - & $\mathrm{R}$ \\
\hline Tamandua tetradactyla & 3 & 0,19 & - & - & $\mathrm{R}$ \\
\hline Cebus nigritus & 3 & 0,19 & - & 9 & $C ?$ \\
\hline Alouatta guariba & - & - & - & $3^{* *}$ & PF? \\
\hline Cerdocyon thous & 65 & 4,05 & 0,255 & 3 & $\mathrm{~F}$ \\
\hline Eira barbara & 16 & 1,00 & 0,095 & 4 & $\mathrm{PF}$ \\
\hline Galictis cuja & - & - & - & 1 & $\mathrm{R}$ \\
\hline Galictis vitatta & - & - & - & - & NR \\
\hline Lontra longicaudis & - & - & $1,000^{*}$ & - & $\mathrm{R}$ \\
\hline Nasua nasua & 82 & 5,11 & 0,165 & 23 & C \\
\hline Procyon cancrivorus & 51 & 3,18 & 0,225 & 4 & PF \\
\hline Leopardus pardalis & 211 & 13,15 & 0,460 & 5 & $C$ \\
\hline Leopardus tigrinus & 1 & 0,06 & 0,060 & - & $\mathrm{R}$ \\
\hline Leopardus wiedii & 1 & 0,06 & 0,095 & - & $\mathrm{R}$ \\
\hline Puma yagouaroundi & 27 & 1,68 & 0,180 & 2 & $\mathrm{PF}$ \\
\hline Puma concolor & 5 & 0,31 & - & 1 & $\mathrm{R}$ \\
\hline Panthera onca & 4 & 0,25 & 0,080 & - & $\mathrm{R}$ \\
\hline Mazama sp. & 44 & 2,74 & 0,395 & 5 & $\mathrm{PF}$ \\
\hline Pecari tajacu & 196 & 12,21 & 0,555 & 18 & $C$ \\
\hline Tayassu pecari & - & - & - & - & EX \\
\hline Tapirus terrestris & 99 & 6,17 & 0,530 & 5 & $\mathrm{~F}$ \\
\hline Cuniculus paca & $1 *$ & - & 0,010 & - & $\mathrm{R}$ \\
\hline Dasyprocta azarae & 432 & 26,92 & 0,940 & 105 & C \\
\hline Hydrochoerus hydrochaeris & 4 & 0,25 & 0,030 & - & $\mathrm{R}$ \\
\hline Coendou spinosus & - & - & - & - & NR \\
\hline Sylvilagus brasiliensis & 334 & 20,81 & 0,490 & 139 & $\mathrm{C}$ \\
\hline Lepus capensis & 2 & 0,12 & - & - & $\mathrm{R}$ \\
\hline Total & 1605 & 100 & - & 327 & \\
\hline
\end{tabular}

Quanto à equitabilidade, não houve diferença significativa entre estações do ano $(\mathrm{F}=3,25 ; \mathrm{p}=0,1794)$ e tampouco entre estradas $(\mathrm{F}=0,02 ; \mathrm{p}=0,8914)$. A equitabilidade apresentou valores de $0,66( \pm 0,08)$ e $0,67( \pm 0,07)$ nas estradas do Porto e Salto respectivamente.

Quando comparadas em termos da composição de espé- cies através do índice de Morisita, novamente não verificam-se diferenças entre as estações $(R=-0,2292 ; p=0,0769)$ e tampouco entre as estradas $(R=0,375 ; p=0,05635)$, embora este último esteja bastante próximo do limite de significância. O mesmo ocorre com o índice de Jaccard entre as estações $(R=-0,1042$; $p=0,7521)$ e entre as estradas $(R=0,07813 ; p=0,2858)$. 


\section{DISCUSSÃO}

Neste estudo obteve-se o registro de 29 espécies de mamíferos de médio e grande porte, das quais, 18 encontram-se sob ameaça de extinção no Estado do Rio Grande do Sul (Fontana et al. 2003), sendo três consideradas como Criticamente Ameaçadas, quatro como Em Perigo e 11 como Vulneráveis. Diante deste quadro, fica clara a importância do Parque Estadual do Turvo nas estratégias de conservação da região sul do Brasil.

Na lista ora apresentada, são acrescidas cinco espécies à lista publicada em 1986 por Wallauer \& Albuquerque. Das espécies citadas nesse trabalho quatro não foram encontradas no presente estudo, Galictis vittata (Schreber, 1776), Mazama gouazoubira (Fischer, 1814), Tayassu pecari e Coendou spinosus (Cuvier, 1822). Dentre as espécies citadas por Wallauer \& Albuquerque (1986), a ocorrência de G. vittata não seria esperada dada à área de distribuição da espécie apresentada por EISEMBERG \& REDFORD (1999) e Emmons \& FeER (1999). No plano de manejo da Unidade (SiLva et al. 2005) são citadas 24 espécies de mamíferos de médio porte, das quais três espécies não foram registradas neste estudo: Dasypus septemcinctus Linnaeus, 1758 citada ocorrendo nas imediações do Parque, e M. gouazoubira, citada como de possível ocorrência e Tayassu pecari. Em relação a este plano de manejo, verifica-se o registro de oito espécies adicionais no presente estudo, sobretudo nos grupos Xenarthra e Didelphimorphia. Tanto em Wallauer \& Albuquerque (1986) quanto em Silva et al. (2005) é citada a presença de T. pecari, espécie que pode ser considerada extinta do PET. Os últimos relatos da espécie remontam ao final da década de 90, quando houve a eliminação de um pequeno bando (10 a 18 animais) na borda do Parque, que provavelmente representava o último local de ocorrência da espécie no Rio Grande do Sul (Mahler JR \& SCHNeider 2003).

Com o trabalho ora apresentado, totaliza-se o registro de 45 espécies de mamíferos no Parque Estadual do Turvo (Tab. I). Dentre estas espécies, pouco é conhecido sobre a diversidade de morcegos, com apenas nove espécies (Walauer \& Albuquerque 1986, Rui \& Fabián 1997, Silva et al. 2005). Ainda mais incipiente é o conhecimento da diversidade de pequenos mamíferos não voadores, Rodentia e Didelphimorphia, dos quais são conhecidas apenas quatro espécies (Walauer \& Albuquerque 1986, Silva et al. 2005).

\section{Frequiência de registros “versus” a abundância real das espécies}

Antes de serem apresentados os dados referentes à abundância relativa, faz-se necessária uma reflexão sobre o que significa a proporção de registros de um determinado método em relação à abundância real das espécies à eles associados. Neste sentido, Jorge (1986) e Walker et al. (2000) afirmam que a freqüência de indícios não representa necessariamente a abundância real da espécie. Embora tal afirmação pareça contraditória em relação aos objetivos propostos pelo presente trabalho, aponta para uma das principais conclusões do estudo: a necessidade de aplicar diversos métodos para acessar dados populacionais. Assim, é necessário levar em consideração a variação entre as taxas de obtenção dos registros analisados e abundância real da espécie (WALKER et al. 2000). Nem sempre é possível a comparação entre os dados obtidos e a realidade, mas em alguns casos, comparações entre métodos podem fornecer dados extremamente relevantes.

Espécies diferentes apresentam diferentes graus de detectabilidade por cada método adotado. Estas diferenças se dão por características biológicas e ecológicas de cada espécie, de forma que podem ser feitas diversas ressalvas, em relação aos métodos adotados.

No que se refere às armadilhas fotográficas, o grau de detectabilidade varia conforme o tamanho e padrões de uso do habitat apresentado pelas diferentes espécies. Assim, espécies maiores tendem a ser mais facilmente fotografadas que espécies menores. Isso porque os modelos de armadilha fotográfica utilizados neste estudo são acionados por infravermelho, que embora programados para funcionarem com o máximo de sensibilidade, permitem que alguns animais, sobretudo pequenos como Sylvilagus brasiliensis, sejam ignorados em algumas ocasiões. Tal fato foi observado com a comparação de resultados de câmeras dispostas frente a frente. Além disso, espécies que têm por hábito deslocar-se longas distâncias por estradas, como Leopardus pardalis, tendem a ser mais fotografadas que espécies que deslocam-se mais por trilhas no interior da mata como Mazama americana (Erxleben, 1777) e Nasua nasua, por exemplo.

Ainda em relação aos registros fotográficos, outra questão importante diz respeito à independência dos registros. No estudo ora apresentado, as câmeras fotográficas estavam programadas com intervalo de 30 segundos entre fotos, ou seja: após um registro, a câmera estaria pronta para um novo registro após 30 segundos. Os dados foram trabalhados com cada foto representando um registro independente, à exceção das análises para o período de atividade. Na maioria das espécies não é possível a individualização por espécime fotografado, de forma que não seria possível afirmar com 100\% de certeza que duas fotos seqüenciais (menos de um minuto) são do mesmo animal. Todavia, certamente há registros seqüenciais do mesmo indivíduo, como pode ser constatado em Leopardus pardalis, que permite a individualização pelo padrão de pelagem, e Tapirus terrestris que possui cicatrizes individuais. Este problema certamente ocorreu em grau ainda maior com Dasyprocta azarae e Sylvilagus brasiliensis, que possuem pequenas áreas de vida e deslocam-se muito pelos mesmos locais. Diversos pesquisadores utilizam um intervalo mínimo entre fotos (usualmente mais de uma hora) definido arbitrariamente. Porém, neste caso, espécies gregárias tem sua abundância relativa subestimada, pois o registro de um grupo inteiro (que pode alcançar dezenas de animais) torna-se equivalente ao registro de um único animal solitário. Desta forma, tais estudos apresentam registros de bandos como espécies individuais, o que certamente não representa de forma adequada a abundância das espécies gregárias. Por outro lado, em estudos como o apresentado aqui, algumas espécies solitárias que possuam alguns in- 
divíduos freqüentemente fotografados, tem sua abundância superestimada em relação a outras espécies cujos indivíduos não transitem da mesma forma diante das câmeras. Tais diferenças de detectabilidade poderiam ser considerados como desvios de amostragem, fato que é inerente a qualquer método de amostragem. Ainda assim, muito provavelmente não haveria modificação no panorama da freqüência de registros, caso não existissem diferenças na detectabilidade das espécies, e certamente $D$. azarae e $S$. brasiliensis, continuariam como as espécies mais freqüentemente registradas.

No que se refere aos rastros, espécies mais pesadas e com cascos (Artiodactyla) ou unhas fortes como Dasyprocta azarae, produzem pegadas mais profundas e duradouras que a de animais mais leves, com patas mais macias que acabam deixando pegadas mais superficiais. Além disso, as pegadas só podem ser encontradas em locais de substrato adequado como estradas e margens de corpos d'água. Muitos animais evitam a utilização destes ambientes, enquanto outros têm nestes locais seu hábitat preferencial, fazendo com que a proporção de registros não seja o reflexo direto da abundância das espécies no ambiente.

Em relação às visualizações, os dados são ainda mais discutíveis. Neste estudo, os dados de visualização foram utilizados apenas quando oportuno, de forma a enriquecer as discussões. Porém, aparentemente as espécies gregárias, com atividade diurna e que utilizam estradas e trilhas com freqüência, tiveram maiores chances de serem registradas.

Certamente dados de abundância obtidos por qualquer método possuem seus vieses. Não há um método perfeito para todas as situações em todos os lugares, mas conjuntos de métodos mais ou menos adequados a cada situação. Por este motivo apresentamos um quadro síntese do status das espécies baseados nas três formas de estimação.

Abundância relativa de mamíferos de médio e grande porte

São raros os dados referentes à abundância relativa de mamíferos de médio e grande porte no Rio Grande do Sul e mesmo no Brasil. Um dos poucos trabalhos a apresentar dados sobre a abundância relativa de grandes mamíferos no Brasil foi realizado no Parque Nacional das Emas (Rodrigues et al. 2002). Este estudo, realizado no bioma do Cerrado permite uma série de comparações com o estudo ora apresentado, embora deva-se levar em conta as diferenças entre os ecossistemas em questão.

No que se refere aos carnívoros, o trabalho de SANTOS et al. (2004) faz referência sobre a abundância do grupo no Parque Nacional dos Aparados da Serra (PNAS), no Rio Grande do Sul. Esta Unidade de Conservação localiza-se na porção nordeste do Estado, e possui uma vegetação diferenciada do Parque Estadual do Turvo, com áreas campestres entremeadas por capões de mata com o domínio de araucárias (Araucaria angustifolia, Bertol.). Nesse estudo, a abundância dos carnívoros é inferida a partir de transectos de visualização e procura por pegadas, com a direção definida aleatoriamente através dos pontos cardeais, dentro de quadrantes pré-determinados. Tal método, embora claramente adotado para obtenção de dados aleatórios, não é totalmente comparável aos dados obtidos no estudo ora apresentado, que fez uso apenas de estradas. Todavia, é sabido que diversos mamíferos têm por hábito deslocarse preferencialmente em trilhas pré-existentes (Tomas \& Miranda 2003), sobretudo carnívoros como os felinos (CRAWSHAW 1997).

A primeira diferença entre os trabalhos diz respeito à composição da comunidade de carnívoros, que no PNAS apresenta três espécies típicas de áreas abertas, Conepatus chinga (Molina 1892), Chrysocyon brachyurus (Illiger, 1815) e Lycalopex gymnocercus (Fischer 1814), que não ocorrem no PET que possui natureza tipicamente florestal. Por outro lado, no PET ocorre a última população de onças pintadas do Rio Grande do Sul. Além disso, os pequenos felinos foram registrados no nível de espécie, diferentemente do estudo supra citado onde foram referidos em nível genérico. A despeito das diferenças da estrutura de paisagem das duas áreas, podem ser observadas diferenças e semelhanças na composição da comunidade. Das espécies que ocorrem em ambas as áreas, as espécies com maior número de registros no PNAS são Procyon cancrivorus e Leopardus pardalis (SANTos et al. 2004) ao passo que P. cancrivorus aparece apenas como o quarto carnívoro em número de registros no PET, enquanto que Leopardus pardalis aparece como carnívoro com o maior número de indícios (Tabs II e III).

Para Rodrigues et al. (2002) os carnívoros com maior número de registros no Parque Nacional das Emas (PNE) foram Chrysocyon brachyurus (Illigier, 1811), Conepatus semistriatus (Boddaert, 1784), Pseudalopex vetulus (Lund, 1842) e Cerdocyon thous (Linnaeus, 1766). Destas, apenas C. thous ocorre no PET cujo número de registros é intermediário, o que pode estar associado ao fato de $C$. thous ser uma espécie característica de ambientes abertos, sendo menos freqüente em ambientes florestados, como o PET (Emmons \& Feer 1999, Oliveira et al. 2007). Entre os carnívoros com menor número de registros no Parque Nacional das Emas estão Nasua nasua e Leopardus pardalis, que são as espécies mais comumente registradas no PET.

Em relação aos demais carnívoros do PET, destaca-se a baixíssima proporção de registros de Leopardus tigrinus, Leopardus wiedii, e Galictis cuja. Tais dados são comparáveis a três áreas na Bolívia, onde Maffer et al. (2002) sugerem que as densidades de gatos pequenos, Puma yagouaroundi e Leopardus geoffroyi (d'Orbigny \& Gervais, 1844), podem ser mais baixas do que de predadores de topo como Panthera onca e Puma concolor. Além disso, MAFFe et al. (2002) obtiveram apenas um registro de Galictis vittata em uma das três áreas avaliadas. Segundo Rodrigues et al. (2002), os pequenos gatos pintados do gênero Leopardus também possuem baixas abundâncias no PNE, assim como Galictis cuja. Para SANTOS et al. (2004) os carnívoros com freqüência mais baixa de registros foram Galictis cuja e Puma yagouaroundi, que no PET apresenta-se com uma freqüência intermediária, sendo o segundo felino em número de registros (Tabs II e III).

Algumas espécies de carnívoros relativamente comuns em outras áreas, tais como Cerdocyon thous e Procyon cancrivorus, possuem no PET uma proporção de registros intermediária. A

Revista Brasileira de Zoologia 24 (4): 1087-1100, dezembro 2007 
Tabela III. Número, proporção de registros e "Captura por Unidade de Esforço" obtidos com armadilhas fotográficas em quatro campanhas entre 2005 e 2006 no Parque Estadual do Turvo.

\begin{tabular}{|c|c|c|c|c|c|c|c|c|c|c|c|c|}
\hline \multirow{2}{*}{ Espécies } & \multicolumn{3}{|c|}{ Porto 2005} & \multicolumn{3}{|c|}{ Salto 2005} & \multicolumn{3}{|c|}{ Porto intensivo } & \multicolumn{3}{|c|}{ Salto intensivo } \\
\hline & $\mathrm{n}$ & $\%$ & CPUE & $\mathrm{n}$ & $\%$ & CPUE & $\mathrm{n}$ & $\%$ & CPUE & $\mathrm{n}$ & $\%$ & CPUE \\
\hline Didelphis albiventris & - & - & - & 6 & 1,80 & 1,86 & - & - & - & - & - & - \\
\hline Didelphis aurita & 7 & 1,61 & 1,74 & 4 & 1,20 & 1,28 & - & - & - & - & - & - \\
\hline Dasypus novemcinctus & 2 & 0,46 & 0,50 & 3 & 0,90 & 0,96 & 2 & 0,43 & 0,42 & 1 & 0,27 & 0,21 \\
\hline Tamandua tetradactyla & 1 & 0,23 & 0,25 & 2 & 0,60 & 0,64 & - & - & - & - & - & - \\
\hline Cebus nigritus & 3 & 0,69 & 0,75 & - & - & - & - & - & - & - & - & - \\
\hline Cerdocyon thous & 37 & 8,53 & 9,20 & 18 & 5,39 & 5,77 & 6 & 1,28 & 1,25 & 4 & 1,08 & 0,83 \\
\hline Nasua nasua & 26 & 5,99 & 6,47 & 17 & 5,09 & 10,5 & 29 & 6,20 & 6,4 & 10 & 2,71 & 2,71 \\
\hline Procyon cancrivorus & 21 & 4,84 & 5,22 & 19 & 5,69 & 6.09 & 4 & 0,85 & 0,83 & 7 & 1,90 & 1,46 \\
\hline Eira barbara & 9 & 2,07 & 2,24 & - & - & - & 3 & 0,64 & 0,63 & 4 & 1,08 & 1,10 \\
\hline Leopardus pardalis & 30 & 6,91 & 7,46 & 68 & 20,4 & 21,8 & 31 & 6,62 & 6,46 & 82 & 22,2 & 17,3 \\
\hline Leopardus tigrinus & - & - & - & - & - & - & 1 & 0,21 & 0,21 & - & - & - \\
\hline Leopardus wiedii & - & - & - & 1 & 0,30 & 0,36 & - & - & - & - & - & - \\
\hline Puma yagouaroundi & 14 & 3,23 & 3,48 & 4 & 1,20 & 2,00 & 8 & 1,71 & 1,67 & 1 & 0,27 & 0,21 \\
\hline Puma concolor & - & - & - & - & - & - & - & - & - & 5 & 1,36 & 1,04 \\
\hline Panthera onca & - & - & - & 4 & 1,20 & 1,28 & - & - & - & - & - & - \\
\hline Tapirus terrestris & 15 & 3,46 & 3,73 & 11 & 3,29 & 3,53 & 48 & 10,3 & 10,0 & 25 & 6,78 & 5,21 \\
\hline Mazama sp. & 3 & 0,69 & 0,75 & 13 & 3,89 & 4,17 & 11 & 2,35 & 2,29 & 17 & 4,61 & 3,73 \\
\hline Pecari tajacu & 38 & 8,76 & 9,45 & 7 & 2,10 & 4,41 & 129 & 27,6 & 26,9 & 22 & 5,96 & 6,55 \\
\hline Dasyprocta azarae & 122 & 28,1 & 30,3 & 45 & 13,5 & 31,7 & 151 & 32,3 & 31,5 & 114 & 30,9 & 32,1 \\
\hline Hydrochoerus hydrochaeris & 1 & 0,23 & 0,25 & - & - & - & 3 & 0,64 & 0,63 & - & - & \\
\hline Sylvilagus brasiliensis & 105 & 24,2 & 26,1 & 110 & 32,9 & 35,3 & 42 & 8,97 & 8,75 & 77 & 20,9 & 16,0 \\
\hline Lepus capensis & - & - & - & 2 & 0,60 & 0,64 & - & - & - & - & - & - \\
\hline
\end{tabular}

ocorrência destas espécies generalistas, que podem ser consideradas como mesopredadores, em proporções comparativamente baixas, pode caracterizar o equilíbrio deste ecossistema, dominado por carnívoros mais especializados e de maior porte como, Panthera onca e Puma concolor.

Outros mamíferos, com baixos números de registros como Dasypus novemcinctus e Didelphis albiventris, abundantes em áreas alteradas também fornece indicativos de que, aparentemente, o ambiente esteja pouco perturbado. Diversas outras espécies apresentaram baixos índices de registros: Chironectes minimus, Didelphis aurita (Wied, 1826), Tamandua tetradactyla, Eupharctus sexcinctus, Alouatta guariba Cabrera, 1940, Cebus nigritus, Eira barbara, Lontra longicaudis, Puma yagouaroundi, Cuniculus paca e Hydrochoerus hydrochaeris, além de outras espécies citadas mais adiante (Tabs II e III). Porém, deve-se levar em conta as particularidades da biologia da maioria destas espécies e suas implicações frente aos métodos aplicados. As espécies $C$. minimus, $L$. longicaudis, $H$. hydrochaeris têm uma clara associação a ambientes aquáticos, que foram pouco amostrados no estudo em questão. Assim, é provável que estas espécies tenham sido subamostradas com aplicação dos métodos utilizados, e sua abun- dâncias reais sejam mais elevadas do que sugere a proporção de registros observados. No caso de $A$. guariba e $C$. nigritus verificam-se atividades predominantemente arbóreas, que faz com que estejam pouco propensos ao registro fotográfico e à impressão de rastros no substrato. No que se refere a $C$. nigritus, esta foi a quinta espécie em número de registros visuais, enquanto que A. guariba foi registrado apenas por sua vocalização característica (Tab. II). Já os baixos registros para T. tetradactyla, podem refletir uma baixa capacidade de suporte da área para a espécie que, apesar de fazer uso do estrato arbóreo, é comumente fotografada no chão em outros ecossistemas e localidades (OliveIrA et al. 2007). A raridade dos registros de Euphractus sexcinctus, espécie comum em áreas alteradas e abertas (EIsEMberg \& REDFord 1999), provavelmente deva ser decorrente do ambiente do PET, florestal e pouco alterado, ser pouco favorável à espécie.

Por outro lado, poucas espécies apresentaram elevados números de registros. As espécies mais registradas foram Dasyprocta azarae, Sylvilagus brasiliensis, Leopardus pardalis e Pecari tajacu (Tabs II e III). Dentre estas D. azarae e S. brasiliensis, representaram juntas quase $50 \%$ dos registros fotográficos, praticamente $75 \%$ das visualizações e estiveram presentes em 94 e $49 \%$ dos 
transectos de pegadas, respectivamente. Das espécies com maior número de registros, L. pardalis, assim como a maioria dos felinos, tem por hábito deslocar-se por trilhas e percorrer longas distâncias. Assim, tendem a ser comumente registrados em armadilhas fotográficas, embora sua densidade apresente-se sempre em níveis consideravelmente inferiores às demais supracitadas.

Dentre as espécies de topo de cadeia, Panthera onca foi a espécie com maior número de registros em 2005, ao passo que Puma concolor aparece como o grande felino mais fotografado em 2006 (Tab. III), quando foram registrados ao menos quatro indivíduos. Em 2005 foram registrados ao menos três indivíduos de $P$. onca na área do PET e pouquíssimos registros de $P$. concolor (Tab. III). Uma das onças-pintadas fotografadas no Turvo foi registrada a $36 \mathrm{~km}$ do Parque, na Argentina (PAviolo et al. 2006) apenas dois meses após o registro no lado brasileiro. Este espécime foi registrado novamente no PET, 16 meses após seu último registro no Parque. Embora o intercâmbio de animais entre o PET e as florestas da região de Misiones na Argentina seja sugerido desde a década de 80 , como fundamental para manutenção da população de P. onca no Parque (Lema 1980, Albuquerque 1985), tal deslocamento jamais havia sido provado. O deslocamento de animais entre a região de Misiones e o PET é relatado por guarda parques para espécies como os veados e a anta, de forma que a migração de animais entre estas áreas é, provavelmente, uma importante forma de manutenção de variabilidade genética nas populações de mamíferos de grande porte do Parque.

Entre os ungulados, somente Pecari tajacu possui elevados índices de registros, sendo a quarta espécie mais registrada (Tabs II e III). Além de ocorrer de forma freqüente segundo todos os métodos adotados, é na maioria das vezes, registrada em bandos, o que permite supor a existência de uma população relativamente numerosa. No caso de T. terrestris, a maioria dos registros é de indivíduos solitários, apesar de haverem diversos registros de fêmeas com filhotes. Finalmente, os veados são registrados em baixas proporções, com Mazama americana sendo a espécie dominante numa proporção de quatro para um em relação à Mazama nana (Henzel, 1872). Mesmo se consideradas em conjunto, Mazama sp. possui menos da metade dos registros de T. terrestris. Para Maffei et al. (2002) Mazama gouazoubira é a espécie de ungulado mais registrado em duas das três áreas avaliadas na Bolívia, e Mazama americana aparece como a espécie menos registrada. No PNE, Rodrigues et al. (2002) também observam Mazama americana como uma espécie pouco abundante. Em ambos os estudos, Tayassu pecari ocorre em maior abundância que Pecari tajacu.

Os registros de pegadas dos ungulados mostraram-se muito mais freqüentes do que a proporção de registros fotográficos (Tab. II), fato que certamente está associado às características de seus rastros, mais profundas e, portanto, mais duradouras do que a maioria dos outros mamíferos. Desta forma, a avaliação da abundância relativa a partir de transectos de pegadas, como adotado neste trabalho, tende a superestimar a proporção de ungulados em relação aos demais mamíferos.

\section{Relação entre abundância relativa e densidade das espécies}

Como dito anteriormente, a freqüência de indícios não está diretamente relacionada à abundância real da espécie (JoRGE 1986, WALKER et al. 2000), mas à sua biologia e como esta influi na detectabilidade dos métodos. O caso que melhor exemplifica esta afirmação é a relação entre Leopardus pardalis e Nasua nasua no Parque Estadual do Turvo (Tab. II). A espécie de carnívoro mais fotografada durante o estudo foi $L$. pardalis, com um total de 211 registros entre janeiro 2005 e julho de 2006, ante 82 de N. nasua no mesmo período. Em relação à proporção de rastros encontrados, o padrão é ainda mais discrepante, com pegadas de L. pardalis em $46 \%$ dos transectos e N. nasua em 16\%. Assim, de acordo com os dois métodos explicitados, seria plausível supor que $L$. pardalis é mais abundante na área do que N. nasua. Porém, por foto-identificação, foram individualizados 28 indivíduos de L. pardalis, em uma população estimada em aproximadamente 35 indivíduos para todo o PET. Por outro lado, se forem consideradas somente duas, das 23 visualizações de $N$. nasua obtidas durante o ano de 2005 (Tab. II), tem-se o registro de dois grupos com mais de 30 indivíduos (um em cada uma das estradas), o que sugere que a população desta espécie seja numericamente superior a de $L$. pardalis, como seria o esperado por ser uma espécie generalista e de menor porte. A densidade média conhecida para N. nasua é de 15,1 \pm 13,2 indivíduos/ $/ \mathrm{km}^{2}$ (Robison \& Redford 1989). Assim, mesmo não havendo um esforço de amostragem padronizado, que permita uma análise estatística das visualizações, a não utilização destes dados levaria a uma visão equivocada da comunidade de carnívoros da área de estudo.

\section{Comparação entre estradas e estações}

Com a comparação entre estradas e as estações do ano, verificou-se a existência de diferenças significativas apenas no que se refere à abundância. Tal fato pode estar relacionado a possíveis variações sazonais de recursos, como alimento e água, fazendo com que determinadas espécies utilizem diferentes áreas do Parque ao longo do ano. No que se refere às diferenças de abundância de indivíduos observadas entre as estradas, é possível que a composição da vegetação, aparentemente mais aberta na área do Salto que na área do Porto, influencie nos padrões de deslocamento dos indivíduos. Com deslocamentos maiores, realizados ao longo das estradas, aumenta a probabilidade de detecção através das armadilhas fotográficas, o que poderia influenciar as estimativas de abundância. Tal hipótese é corroborada com dados de deslocamentos de L. pardalis, onde foi possível a individualização através do padrão da pelagem. Na estrada do Porto a média de deslocamento de cinco indivíduos foi de $1740 \mathrm{~m}$, ante $3200 \mathrm{~m}$ para 10 indivíduos na estrada do Salto.

Para todos os demais índices analisados, riqueza de espécies, equitabilidade e composição das espécies os resultados não demonstraram diferenças significativas. Apesar do índice de Morisita mostrar-se muito próximo do limite de significância $(\alpha=0,05)$, fazendo com que não se possa afirmar com absoluta 
certeza sobre a igualdade da composição entre as estradas, é muito provável que a composição entre as estradas seja a mesma. Assim, aparentemente não há um grande impacto do turismo realizado na estrada do Salto, sobre os mamíferos de médio e grande porte ocorrentes nesta área do Parque. Todavia, estes são dados preliminares, e devem ser considerados com cuidado, pois refletem uma visão geral sobre a comunidade de mamíferos local. Não obstante, a avaliação do impacto do turismo não foi um dos objetivos do projeto, para o qual seriam necessários métodos específicos de avaliação.

\section{Conservação de mamíferos do Turvo}

Tomando por base os diversos tipos estimadores realizados, podemos chegar à uma idéia geral acerca do status das espécies de mamíferos de médio e grande porte do PET (Tab. II) Entretanto, diante dos dados apresentados, verifica-se a necessidade urgente de avaliações da densidade e abundância absoluta das espécies ameaçadas que ainda ocorrem na unidade. Além de dados "demográficos", fazem-se necessários estudos ligados à medicina da conservação, verificando a saúde genética e clínica da comunidade de mamíferos locais. Através disso, poderão ser traçadas estratégias de conservação específicas e analisada a necessidade de manejo ativo das populações, que podem ser demasiado pequenas para manterem-se a longo prazo, caso isoladas. A possibilidade de tal isolamento pode ser agravada pela implantação de hidrelétricas no Rio Uruguai. Neste caso, a migração de indivíduos entre as áreas do Turvo e de Misiones poderia ser dificultada ou mesmo impedida, o que representaria um grande impacto sobre as populações do Parque Estadual do Turvo.

Porém, os problemas de conservação dos mamíferos de grande porte do PET não se resumem apenas ao pequeno tamanho do Parque e a seu relativo isolamento. Outra grande ameaça, talvez a maior delas, está relacionada à caça. A caça ilegal no Parque Estadual do Turvo se dá quase que exclusivamente sobre a anta, os veados e a paca, que figuram como animais relativamente raros do Parque. Esta atividade destina-se exclusivamente ao comércio de carne de caça alcançando, segundo relatos, cidades a mais de $500 \mathrm{~km}$ do Parque. Esta ameaça é de conhecimento generalizado, tanto de guarda-parques quanto de administradores, e mostra a fragilidade desta importante área de conservação.

Finalmente, destaca-se a necessidade de esforços internacionais para preservação do Corredor Verde de Misiones, como única forma de assegurar a manutenção a longo prazo da comunidade de mamíferos de grande porte desta grande região que inclui o Parque Estadual do Turvo, o Parque Nacional do Iguaçu e diversas unidades de conservação argentinas. Provavelmente nenhuma destas unidades poderá manter populações de grandes mamíferos a longo prazo, caso isolada. O processo de destruição desta região é intenso, reduzindo dia a dia as possibilidades de conservação dos grandes mamíferos que subsistem neste ambiente. Como cita Redford (1997) "Não deixemos que imagens de satélite nos iludam, pois mais do que florestas estamos perdendo sua fauna, e uma floresta vazia é uma floresta condenada".

\section{AGRADECIMENTOS}

À Fundação O Boticário de Proteção à Natureza pelo financiamento destes estudos, ao $\mathrm{CNPq}$ pela bolsa de mestrado concedida ao PPG Biologia Animal da UFRGS e a Theris por ter encampado o projeto. A Milton de S. Mendonça Jr por sua preciosa ajuda na análise estatística dos dados obtidos. A Flávio H.G. Rodrigues, Mario Di Bitetti e Sandra M. Hartz, por suas críticas e sugestões ao manuscrito deste artigo. À Divisão de Unidades de Conservação da SEMA-RS por permitir e oferecer condições ao desenvolvimento dos trabalhos no Parque Estadual do Turvo.

\section{REFERÊNCIAS BIBLIOGRÁFICAS}

Albuquerque, E.P. 1977. Sobre o desaparecimento da fauna da região do Alto Uruguai e a Importância do Parque Florestal Estadual do Turvo na sua preservação. Roessléria 1 (1): 143149.

Albuquerque, E.P. 1985. Considerações sobre a necessidade de Pesquisa em Conservação biológica nos parques estaduais do Rio Grande do Sul. Roessléria 7 (3): 200-205.

BeCKer, M. \& J.C. Dalponte. 1991. Rastros de mamíferos silvestres brasileiros. Brasília, Universidade de Brasília, 180p.

Brack, P.; R.M. Bueno; D.B. Falkenberg; M.R.C. Paiva; M. Sobral \& J.R. Stehmann. 1985. Levantamento florístico do Parque Estadual do Turvo, Tenente Portela, Rio Grande do Sul, Brasil. Roessléria 7 (1): 69-94.

Carbone, C.; S. Christie; K. Conforti; T. Coulson; N. Franklin; J.R. Ginsberg; M. Griffiths; J. Holden; K. Kawanishi; M. Kinnaird; A. Laidlaw; A. Lyanam; D.W. Macdonald; D. Martyr; C. Macdougal; L. Nath; T. O’Brien; J. Seidensticher; D.J.L. Smith; M. Sunquist; R. Tilson \& W.N. Wan Shahruddin. 2001. The use of photographic rates to estimate densites of tigers and other cryptic mammals. Animal Conservation 4 (1): 75-79.

Cerqueira, R. 2001. Um sistema de monitoramento e inventário da biodiversidade terrestre do Brasil. In: I. Garay \& B. Dias (Orgs.) Conservação e Biodiversidade em ecossitemas Tropicais. Editora Vozes, 430p.

Clarke, K. R. \& R. H. Green. 1998. Statistical design and analysis for a "biological effects" study. Marine Ecology Progress Series 92: 213-226.

Crawshaw Jr, P.G. 1997. Recomendações para um modelo de pesquisa sobre felídeos neotropicais, p. 70-94. In: C. VALLARESPÁDUA \& R.E. BoDMER (Eds). Manejo e conservação de vida silvestre no Brasil. Belém, MCT, CNPq, Sociedade Civil Mamirauá, 285p.

Cullen JR, L. \& R. Rudran. 2003. Transectos lineares na estimative de densidade de mamíferos e aves de grande porte, p. 169179. In: L. Cullen Jr; R. Rudran \& C. Valladares-Padua (Eds). Métodos de estudo em biologia da conservação e manejo da vida silvestre. Curitiba, Editora UFPR, 667p.

Di Bitteti, M.S.; A. PAviolo \& C. DE Angelo. 2006. Density, habitat use and activity patterns of ocelots (Leopardus pardalis) in the Atlantic Forest of Misiones, Argentina. Journal of Zoology 270 (1): 153-163. 
Eisenberg, J.F. \& K.H. Redford. 1999. Mammals of the Neotropics: the Central Neotropics. Chicago, The University of Chicago Press, vol. 3, 609p.

EMmons, L. \& F. FeER, F. 1999. Neotropical Rainforest Mammals: a field guide. Chicago, University of Chicago Press, $2^{\text {nd }}$ ed., $307 p$.

FontAnA, C.S.; G.A. BENCKe. \& R.E. ReIs. 2003. Livro vermelho da fauna ameaçada de extinção no Rio Grande do Sul. Porto Alegre, Edipucrs, 632p.

Hammer, A.; D.A.T. Harper \& P.D. Ryan. 2001. PASt: Paleontological Statistics Software Package for Education and Data Analysis. Palaeontologia Electronica 4. Available at: http://palaeo-electronica.org/2001_1/past/issue1_01.htm [Accessed in 23.VIII.2006]

Jorge, J.L.T. 1986. Manual para el censo de los vertebrados terrestres. Madrid, Editora Raíces, 278p.

Karanth, U. 1995. Estimating Tiger Panthera tigris Populations from Camera-Trap Data Using Capture-Recapture Models. Biological Conservation 71: 333-338.

Karanth, U. \& J.D. Nichols. 1998. Estimation of Tiger in India Using Photographic Captures and Recaptures. Ecology 79 (8): 2852-2862.

Lema, T. 1980. Importância da fauna do Parque do Turvo, RS. Ciência e Cultura 32 (3): 328-330.

Maffei, L.; E. CuÉllar \& A. Noss. 2002. Uso de trapas cámera para la evaluación de mamíferos em el ecotono chaco-chiquitanía. Revista Boliviana de Ecologia y Conservacion Ambiental 11: 55-65.

Maffei, L.; E. Cú́llar, E. \& A. Noss. 2004. One thousand jaguars (Panthera onca) in Bolivia's Chaco? Camera trapping in the Kaa-Iya National Park. Journal of Zoology 262 (1): 295304.

MÄHLer Jr, J.K.F. \& M. Schneider. 2003. Ungulados, p. 547-5565. In: C.S. Fontana; G.A. Bencke \& R.E. Reis (Eds). Livro vermelho da fauna ameaçada de extinção no Rio Grande do Sul. Porto Alegre, Edipucrs, 632p.

Oliveira, T.G. 1994. Neotropical Cats: ecology and conservation. São Luiz, EDUFMA, 220p.

Oliveira, T.G. \& K. Cassaro. 2005. Guia de campo dos felinos brasileiros. São Paulo, Instituto Pro Carnívoros, Fundação Parque Zoológico de São Paulo, Sociedade de Zoológicos do Brasil, Pró Vida Brasil, 80p.

Oliveira, T.G.de; P.A. Dias; O. Quixaba-Vieira; D.M. Ibanes; J.P. Santos; \& R.C. Paula. 2007. Mamíferos do Cerrado norte do Brasil, p. 261-285. In: L. BARRETO (Ed.). Cerrado norte do Brasil. Pelotas, USEB, 378p.

Pardini, R.; E.H. DitT; L. Cullen Jr; C. Bassi \& R. Rudran. 2003. Levantamento rápido de mamíferos terrestres de médio e grande porte, p. 181-201. In: L. Cullen JR; R. Rudran \& C. Valladares-Padua (Eds). Métodos de estudo em biologia da conservação e manejo da vida silvestre. Curitiba, Editora UFPR, 667p.

Paviolo, A.; C. De Ângelo; Y. Di Blanco; C. Ferrari; M. Di Bitetti;
C.B. Kasper; F. Mazim; J.B.G. Soares \& T.G. Oliveira. 2006. The Need of Transboundary Efforts to Preserve the Southernmost Jaguar Population in the World. Cat News 45: 12-14.

Redford, K.H. 1997. A Floresta Vazia, p. 1-26. In: C. VallaresPÁDUA \& R. E. BODMER (Eds). Manejo e conservação de vida silvestre no Brasil. Belém, MCT, CNPq, Sociedade Civil Mamirauá, 285p.

Reis, N.R.; A.L. Peracchi; W.A. Pedro \& I.P. Lima. 2006. Mamíferos do Brasil. Londrina, Nélio R. Reis, 437p.

Robison, J.G. \& K.H. Redford. 1989. Body size, diet, and population variation in Neotropical forest mammal species: predictors of local extinction? p. 567-594 In: K.H. REDFORD \& J.F. Eisemberg (Eds). Advances in Neotropical Mammalogy. Gainesville, Sandhill Crane Press, 614p.

Rodrigues, F.H.G.; L. Silveira; A.T.A. Jácomo; A.P. Carmignotto; A.M.R. Bezerra; D.C. Coelho; H. Garbogini; J. Pagnozzi \& A. Hass. 2002. Composição e caracterização da fauna de mamíferos do Parque Nacional das Emas, Goiás, Brasil. Revista Brasileira de Zoologia 19 (2): 589-600.

Ruı, A.M. \& M.E. Fabián. 1997. Quirópteros de la familia Phyllostomidae (Mammalia, Chiroptera) en Selvas del estado de Rio Grande do Sul, Brasil. Chiroptera Neotropical 3 (2): 75-77.

Santos, M.F.M.; M. Pellanda; A.C. Tomazzoni; H. Hasenack \& S.M. HarTz. 2004. Mamíferos carnívoros e sua relação com a diversidade de hábitats no Parque Nacional dos Aparados da Serra, sul do Brasil. Iheringia, Série Zoologia, 94 (3): 235 245.

Silva, C.P.; J.K.F. Mähler Jr; S.B. Marcuzzo \& S. Ferreira. 2005. Plano de manejo do Parque Estadual do Turvo. Porto Alegre, Secretaria Estadual de Meio Ambiente, 355p.

Sokal, R.R. \& F.G. Rohlf. 1995. Biometry. New York, W.H. Freeman, $3^{\text {rd }}$ ed., 887p.

Tomas, W.M. \& G.H.B. Miranda. 2003. Uso de armadilhas fotográficas em levantamentos populacionais, p. 243-267. In: L. Cullen Jr; R. Rudran \& C. Valladares-Padua (Eds). Métodos de estudo em biologia da conservação e manejo da vida silvestre. Curitiba, Editora UFPR, 667p.

Travi, V.H. \& M.C. Gaetani. 1985. Guia de pegadas para a identificação de mamíferos silvestres do Rio Grande do Sul. Veritas 30 (117): 77-92.

Trolle, M. \& M. Kéry. 2003. Estimation of Ocelot Density in the Pantanal Using Capture-Recapture Analysis of CameraTraping Data. Journal of Mammalogy 84 (2): 607-614.

Voss, R.S. \& L.H. Emmons. 1996. Mammalian diversity in Neotropical lowland rainforest: preliminary assessment. Bulletin of the American Museun of Natural History 230: 1-117.

Walker, R.S.; A.J. Novaro \& J.D. Nichols. 2000. Consideraciones para la estimación de abundancia de poblaciones de mamíferos. Mastozoologia Neotropical, Journal of Neotropical Mammalogy 7 (2): 73-80.

Wallace, R.B.; H. Gómez; G. Ayala. \& F. Spinoza. 2003. Camera traping for jaguar (Panthera onca) in the Tuichi Valley, 
Bolivia. Mastozoologia Neotropical, Journal of Neotropical Mammalogy 10 (1): 133-139.

Wallauer, J.P. \& E.P. Albuquerque. 1986. Lista preliminar dos mamíferos de observados no Parque Estadual do Turvo, Tenente Portela, Rio Grande do Sul, Brasil. Roessléria 8 (2): 179-185.
Wemmer, C.; T.H. Kunz; G. Lundie-Jenkins \& W. McShea. 1996. Mammalian Sign, p. 157-176. In: D.E. Wilson; F.R. Cole; J.D. Nichols; R. Rudran \& M.S. Foster (Eds). Mensuring and monitoring biological diversity: standart methods for mammals. Washington, Smithsonian Institution Press, 409p.

Recebido em 27.IV.2007; aceito em 26.XI.2007. 